\title{
Integrating 21st Century Skills in Higher Education Engineering Curricula
}

\author{
https://doi.org/10.3991/ijac.v13i2.17011
}

\author{
Sigrid Schefer-Wenzl ( $\left.{ }^{\bowtie}\right)$, Igor Miladinovic \\ University of Applied Sciences Campus Vienna, Austria \\ sigrid.schefer-wenzl@fh-campuswien.ac.at
}

\begin{abstract}
Engineering studies are often too focused on the development of engineering skills. This results in graduates with deficits in $21^{\text {st }}$ century skills, such as complex problem solving, teamwork, or communication skills. To address this issue, sophisticated concepts need to be introduced in order to attractively include $21^{\text {st }}$ century skills into engineering curricula. This paper presents related concepts, which we have applied in the engineering degree programs, and discusses their benefits and drawbacks according to our experiences. We also provide recommendations about integrating $21^{\text {st }}$ century skills courses into engineering curricula.
\end{abstract}

Keywords - 21st Century Skills, Engineering Education, E-Learning.

\section{$1 \quad$ Introduction}

Industry trends show an increased need for highly skilled software engineers, having a blend of both technical and professional skills. While technical skills include domainspecific knowledge, such as programming, mastering computer networks, and developing electronic components, professional skills are related to competencies needed for a profession beyond technical skills. Examples are complex problem solving, teamwork, and communication skills-skills that can be applied in different areas, jobs, and situations. Therefore, they are also referred to as 21 st century skills, emphasizing their growing importance for modern employees contributing to the 4th industrial revolution $[1,2]$.

As engineering studies mainly focus on developing rigorous technical expertise, the time devoted to professional skills development in an engineering curriculum is often limited. Frequently, professional skills are regarded as essential differentiators between applicants for a job position. The successful applicants must be able to communicate their ideas, show intercultural competencies, work in teams, and demonstrate problemsolving skills.

The goal of this paper is to address the possibilities of integrating 21 st century skills into an engineering curriculum. To achieve this, we will present different existing elearning-based approaches and evaluate their strengths and weaknesses based on our experiences in two study programs at the UAS FH Campus Wien, i.e., the bachelor 
degree program Computer Science and Digital Communications and the master degree program Software Design and Engineering.

An extensive literature survey on different best practices for integrating 21 st century skills into engineering studies showed that many contributions state the importance of developing 21 st century skills for engineers. However, there are only a few concrete examples of how these skills can be systematically developed across any curriculum.

We have also invited representatives from leading national and international industry partners and collected inputs on important skills of future engineering graduates. They confirmed the importance of 21 st century skills, even putting them above technical skills, as companies can quickly compensate some deficits in technical skills via targeted courses, offered internally or externally. The development of 21st century skills, in contrast, usually takes longer. Thus, it should be a fixed element in any degree program, particularly in engineering studies.

From these inputs, we selected a set of 21 st century skills for our two study programs. The next challenge was to find an optimal way to integrate them into the curricula of modern engineering studies, since we were facing difficulties among students to recognize the importance of 21st century skills.

Based on our experiences, we provide a set of recommendations for using blended learning concepts to introduce professional skills into curricula of engineering studies in this paper. They should help to create successful e-learning environments for the education of future engineering professionals.

\section{$2 \quad$ Teaching $21^{\text {st }}$ Century Skills}

Employees of the $21^{\text {st }}$ century are required to apply their knowledge and skills in unknown and evolving circumstances. This is particularly true for engineering jobs, as people in this sector usually deal with interdisciplinary projects in rapidly changing and globally distributed environments. To be prepared for the future, engineering students need to develop a broad spectrum of skills and competencies besides technical skills. Several studies highlight skills such as critical and creative thinking, problem solving, as well as communication and collaboration skills [3,4]. Students have to learn to think in more integrated ways, considering interconnections and relations between the perspectives of different disciplines.

One of the main reasons for students' low acceptance of courses related to $21^{\text {st }}$ century skills in engineering studies is a lack of recognition of their relevance. Engineering students are usually curious to learn about engineering topics and oversee the importance of $21^{\text {st }}$ century skills in professional environments. Therefore, the introduction of $21^{\text {st }}$ century skills in an engineering degree program is a trade-off between the attractiveness of the curriculum for students and the attractiveness of graduates for companies.

In our study programs, we address this issue with several different methods, depending on the topic and the semester in the program. These methods can be structured into four categories: 
- Isolated - courses for 21 st century skills are held independently from other courses.

- Module - a 21st century skill course is interconnected with an engineering course in a module; a single grade is given for the module.

- Integrated - the focus of a course is on the development of engineering skills. However, the application of some of the 21 st century skills is necessary to complete the course successfully.

- Interdisciplinary - the course is a complex project among several disciplines, like engineering, health, manufacturing, or law. The success of the project directly depends on 21 st century skills of the students.

In the next subsections, we will discuss how e-learning can be applied in each of these categories, and give relevant examples.

\subsection{Isolated}

Isolated courses are the traditional way of teaching $21^{\text {st }}$ century skills. In our study programs, $21^{\text {st }}$ century skills courses are offered in the last two semesters for topics that are difficult to combine with other courses offered during that time. Examples are "Business Administration", "Legal IT Aspects", and "Entrepreneurship".

In these courses, e-learning concepts include an e-learning platform with distance learning exercises without a particular focus on engineering topics.

\section{$2.2 \quad$ Module}

In this category, we have combined $21^{\text {st }}$ century skills courses with a suitable technical course, starting with the first semester, which includes a combination of the course "Team Work" with "Programming 1". Thus, students first learn theory on teamwork and do a variety of team exercises. Afterwards they apply selected methods in the context of a programming course, solving different programming exercises in small groups. Special attention is paid to how teamwork is organized, the extent of collaboration and conflict resolution. For both courses, students receive a single grade, depending on their overall performance. This way the students are immediately able to realize the benefit of the professional courses.

Subsequently, in each of the first four semesters of the bachelor degree program and in the first two semesters of the master degree program, we have introduced at least one such combination. First results show a high acceptance of this concept among students.

The "Complex Problem Solving" master level course has been combined with the "Software Integration" course, expecting students to apply complex problem solving methods on problems in a real software integration project. In a mix of in-class and elearning units, the students work on defined tasks, supported by their lecturers. The course comprises several modules, each of which starts with an e-learning supported distance learning phase, followed by an in-class unit to deepen the obtained knowledge. After the last module, the students apply their complex problem solving skills on a concrete software integration project. A detailed description of this concept can be found in [5]. 


\subsection{Integrated}

The learning goals of integrated courses include development of both technical and $21^{\text {st }}$ century skills. For example, in the mobile learning-based course "Mobile App Development", the technical skills are taught explicitly in a lecture part, whereas $21^{\text {st }}$ century skills are implicitly required for the tutorial part. This allows students to apply $21^{\text {st }}$ century skills in a technical environment immediately.

We designed this blended learning course module by integrating a set of selected teaching methods. In particular, we combined mobile learning with Just-in-Time Teaching (JiTT) elements, learning diaries, project-based learning, coaching and peer learning. In this e-learning concept, smartphones and tablets serve a triple didactic function, as the primary learning medium, as the programming and testing medium, and as the communication and collaboration medium. Parts of our course concept have been published in [6-9].

In addition, in several courses we organize an e-learning-supported hackathon event [10], which supports team formation, and provides an opportunity to creatively develop and assess ideas via virtual or face-to-face interactions. It increases motivation of the participants to put a lot of effort into realizing their ideas [11], which are usually related to software development.

\section{$2.4 \quad$ Interdisciplinary}

In this category of courses, students are working on concrete problems from different disciplines. The particular tasks originate from our industry partners and reflect reallife issues. For subjects related to the specific discipline, the students are supervised by both our lecturers for engineering subjects and representatives of our industry partners. The permanent interaction among different stakeholders fosters the development of $21^{\text {st }}$ century skills, such as complex problem solving, teamwork, as well as communication and presentation skills.

E-learning environments are primarily used for communication, collaboration and documentation. The students are able to get feedback on the progress of the projects frequently, and to react on possible changes. According to our observations, this reduces the risk of a project failure.

\section{Recommendations}

After successfully teaching the first semesters with implemented categories for teaching 21 st century skills, we have derived a set of recommendations for introducing professional skills into curricula of engineering studies. They should help to create successful curricula for the education of future engineering professionals.

First, we have considered the administration efforts for each category. Administration efforts include additional efforts for coordination between the lecturers. 


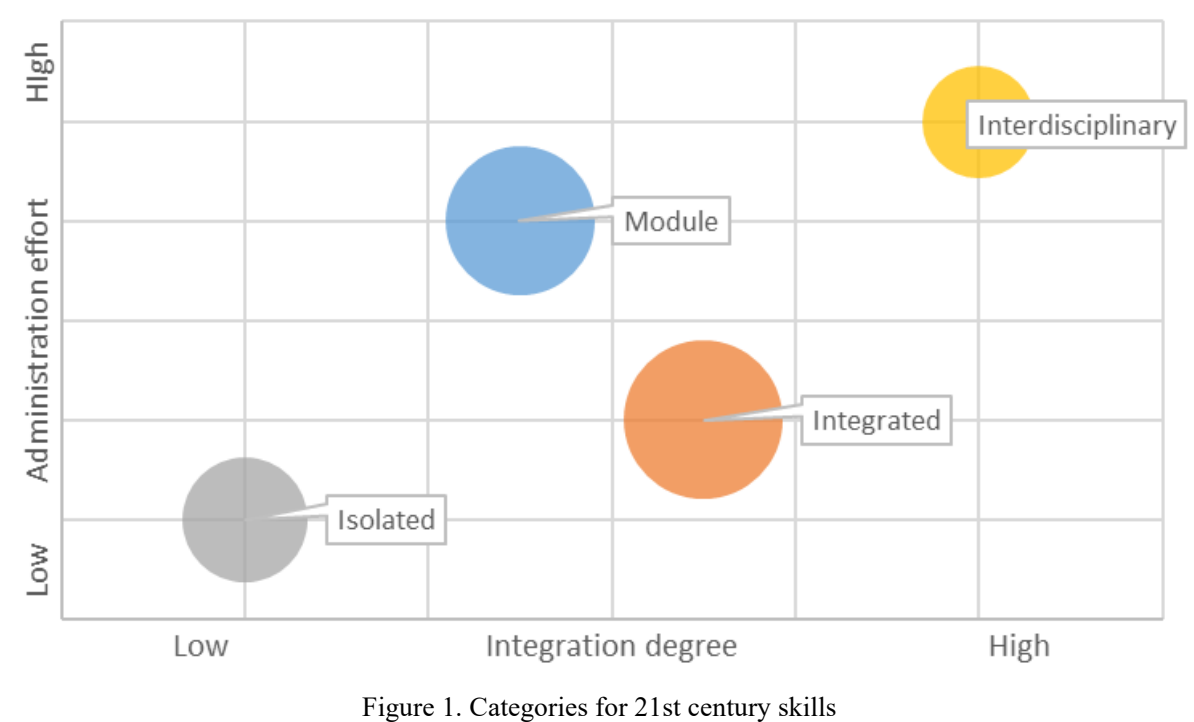

Our experience shows that these efforts are low for Isolated category courses, moderate for Integrated category courses, relatively high for Module category courses and very high for Interdisciplinary category courses. On the other side, the integration level between engineering and 21st century skills also differs among the categories. Figure 1 illustrates the administration effort and the integration level of each category. The size of the bubbles corresponds to the number of courses in our curricula of that category. It can be seen that most of the courses apply the Integrated approach, followed by Module, Isolated and Interdisciplinary approach. A reason for this is that Interdisciplinary category courses are suitable for students in higher semesters only, whereas other categories are rather distributed over the program.

We recommend including $21^{\text {st }}$ century skills in the curriculum starting with the first semester. In the past, we were faced with low motivation of our students, who were primarily interested in technical areas rather than $21^{\text {st }}$ century skills courses. To mitigate this issue, we interconnected $21^{\text {st }}$ century skills courses with technical courses and combined them into modules, which are commonly evaluated and graded. Therefore, we recommend starting with Module category courses in earlier semesters of an engineering degree program to increase students' acceptance of $21^{\text {st }}$ century skills courses. Thereafter, Integrated and Isolated category courses can be introduced gradually. In the advanced semesters of the study, Interdisciplinary category courses can be introduced, since students have at least intermediate knowledge in both engineering and $21^{\text {st }}$ century skills areas.

E-learning concepts can help to lower administration efforts, as they support communication and coordination between lecturers as well as between students and lecturers. Furthermore, they can serve as a knowledge repository, making best practice examples and lessons learned structured and available for everyone. 


\section{Conclusion}

In an engineering degree program, the development of 21st century skills is gaining importance. Therefore, integrating 21 st century skills in engineering curricula is a challenging task. In this paper, we discussed four categories of integrating 21 st century skills in engineering studies. We also provided recommendations and examples for the integration of each category. In our future work we will further apply e-learning concepts and investigate to what extent they can reduce the administration efforts of some of the categories.

\section{$5 \quad$ References}

[1] F. Sanchez Carracedo at al., "Competency Maps: an Effective Model to Integrate Professional Competencies Across a STEM Curriculum," In Journal of Science Education and Technology vol. 27, pp. 448-468, 2018. https://doi.org/10.1007/s10956-018-9735-3

[2] H. Jang, "Identifying 21 st Century STEM competencies using workplace data," In Journal of Science Education and Technology, Vol. 25, Nr. 2, pp. 284-301, 2016. https://doi.org/ 10.1007/s10956-015-9593-1

[3] OECD. "The Future of Education and Skills. Education 2030", 2018 URL: https://www.oecd.org/education/2030/E203020Position20Paper20(05.04.2018).pdf

[4] Council of Europe, "Reference Framework of Competences for Democratic Culture. Volume 2", Council of Europe Publishing, Strasbourg, 2018, URL: https://rm.coe.int/prems008418-gbr-2508-reference-framework-of-competences-vol-2-8573-co/16807bc66d

[5] S. Schefer-Wenzl and I. Miladinovic, „Developing Complex Problem-Solving Skills: An Engineering Perspective", International Journal of Advanced Corporate Learning (iJAC), 2019. https://doi.org/10.3991/ijac.v12i3.11067

[6] S. Schefer-Wenzl and I. Miladinovic, "Game Changing Mobile Learning Based Method Mix for Teaching Software Development," in mLearn 2017, 16th World Conference on Mobile and Contextual Learning, 2017. https://doi.org/10.1145/3136907.3136912

[7] S. Schefer-Wenzl and I. Miladinovic, "Leveraging collaborative mobile learning for sustained software development skills," in Proc. of the 21 International Conference on Interactive Collaborative Learning, September 2018. https://doi.org/10.1007/978-3-030$\underline{11932-4 \quad 16}$

[8] S. Schefer-Wenzl and I. Miladinovic, "Applying a Threefold Gamification Approach in Software Engineering Education," in Proc. of the ICELW 2018, The International Conference on E-Learning in the Workplace, 2018.

[9] S. Schefer-Wenzl and I. Miladinovic, "Learning Diaries-A Valuable Companion of Mobile Learning for Higher Education in Software Engineering, "in Proc. of the IMCL 2019, the International Conference on Interactive Mobile Communication, 2019.

[10] Erik H. Trainer, Arun Kalyanasundaram, Chalalai Chaihirunkarn, and James D. Herbsleb, "How to Hackathon: Socio-technical Tradeoffs in Brief, Intensive Collocation. In Proceedings of the 19th ACM Conference on Computer-Supported Cooperative Work \& Social Computing (CSCW '16). ACM, New York, NY, USA, 2016. $\underline{\text { https://doi.org/10.1145/281 }}$ $\underline{8048.2819946}$

[11] Alexander Nolte, Ei Pa Pa Pe-Than, Anna Filippova, Christian Bird, Steve Scallen and James D. Herbsleb, "You Hacked and Now What? - Exploring Outcomes of a Corporate 
Hackathon", in Proc. of ACM Hum. -Comput. Interact. 2, CSCW, Article 129,2018. https://doi.org/10.1145/3274398

\section{Authors}

Sigrid Schefer-Wenzl is a senior researcher and lecturer at the University of Applied Sciences "FH Campus Wien", Vienna, Austria (e-mail: sigrid.scheferwenzl@fh-campuswien.ac.at).

Igor Miladinovic is head of the degree program "Computer Science and Digital Communications" and "Software Design and Engineering" at the University of Applied Sciences "FH Campus Wien", Vienna, Austria (e-mail: igor.miladinovic@fhcampuswien.ac.at).

Article submitted 2020-07-13. Resubmitted 2020-08-10. Final acceptance 2020-08-15. Final version published as submitted by the authors. 